\title{
A "by-productless" cellulose foaming agent for use in imidazolium ionic liquids
}

\author{
Janet L. Scott, $\dagger^{* a}$ Gianfranco Unali $^{a}$ and Alvise Perosa ${ }^{b}$ \\ Received 19th November 2010, Accepted 4th January 2011 \\ DOI: $10.1039 / \mathbf{c 0 c c 0 5 0 5 7 a}$
}

Cellulose foams, or sponges, are produced from solutions in ionic liquids by the aqueous acid mediated decomposition of 1-alkyl-3methylimidazolium-2-carboxylates, where the alkyl group and acid may be selected such that the by-product is the ionic liquid solvent: a by-productless foaming.

Foamed polymers are used in many diverse applications where lightweight, insulation or absorbancy are desirable. As well as providing large bulk for small quantities of polymer, foaming may also confer vastly increased surface area to mass ratio. This latter is of interest where, for example, catalysts or other active agents are encapsulated, or doped, into the foamed polymer or where a large, accessible surface area is required for surface attachment of active species. Cellulose derivatives, such as cellulose acetate or propionate, may be foamed in similar manner to other thermoplastics, but foaming of cellulose itself has usually been restricted to the preparation of viscose foams via the xanthate process, which entails reaction with $\mathrm{CS}_{2}$ followed by regeneration of cellulose in reactive coagulating baths. ${ }^{1}$ Introduction of porogens, or other foaming agents, during the coagulation/regeneration step leads to the formation of cellulose masses containing voids or cells. Thus, cellulose foams or sponges are usually prepared by casting a solution of cellulose xanthate over a sacrificial void former, ${ }^{2,3}$ such as sodium sulfate decahydrate, $\mathrm{Na}_{2} \mathrm{SO}_{4} \cdot 10 \mathrm{H}_{2} \mathrm{O} .{ }^{4}$ The salt serves the purposes of (a) filling space, thus creating voids in the structure; (b) acting as a reservoir of water; and (c) forming an acid solution on partial dissolution thus aiding decomposition of the xanthate (on application of heat) to yield cellulose. In this process $\mathrm{CS}_{2}$ must be removed during regeneration and the foam well washed to remove residual $\mathrm{Na}_{2} \mathrm{SO}_{4}$. Similar porogens, combined with blowing agents azodicarbonimide or $\mathrm{NaHCO}_{3}$, may be applied in the formation of cellulose foams from solutions in wet $N$-methylmorpholine- $N$-oxide (NMMO); the "Lyocell" process. ${ }^{5}$

\footnotetext{
${ }^{a}$ Unilever Home and Personal Care R\&D Port Sunlight, Quarry Road East, Port Sunlight, CH63 3JW, UK.

E-mail: Gianfranco.Unali@Unilever.com

${ }^{b}$ Dipartimento di Scienze Molecolari e Nanosistemi, Università Ca'

Foscari Venezia, Dorsoduro 2137, 30123 Venezia, Italy.

E-mail:alvise@unive.it

$\dagger$ Current address: Centre for Sustainable Chemical Technologies,

University of Bath, Bath, BA2 7AY, UK. Email: J.L.Scott@bath.ac.uk.
}

Rogers et al. have described the dissolution of cellulose in imidazolium ionic liquids ${ }^{6}$ as a means to prepare cellulose based bioactive films, ${ }^{7}$ biocatalyst supports, ${ }^{8}$ sensors, ${ }^{9}$ and composites. ${ }^{10}$ Others have enthusiastically adopted this new way of processing cellulose without derivatisation (except possibly at chain ends ${ }^{11}$ ) to prepare composite materials, ${ }^{12}$ and to provide dissolved cellulose for solution phase chemistry. ${ }^{13}$ Recently Deng et al. have described direct coagulation of cellulose from ionic liquid (IL) solution and freeze drying to yield "nanoporous" foams, ${ }^{14}$ but this methodology does not provide macroporous materials. As 1-ethyl-3-methylimidazolium acetate [emim][acetate] is the least hazardous or environmentally damaging of these ionic liquids, its use in the development of new generation of cellulose based materials is being pursued industrially. ${ }^{15}$ While one might envisage the preparation of cellulose sponges from such solutions in a process analogous to that used in the formation of Lyocell sponges (i.e. by the use of solid porogens, which are later removed by dissolution, during the coagulation step), such processes do not generally yield foams with very thin cell walls (light foams). In addition, the ionic liquid solvent will be mixed with the solution products of the salts used as porogens, thus complicating essential recycling processes. An alternative means of foaming soluble polymers is by the use of reactive blowing agents. Cellulose dissolved in IL is usually coagulated by exposure to an anti-solvent, such as water, thus, an agent that releases gas on contact with water would serve as a blowing or foaming agent.

To test the concept we chose $\mathrm{NaHCO}_{3}$, which reacts with dilute aqueous acid solutions to yield $\mathrm{CO}_{2}$ (and $\mathrm{H}_{2} \mathrm{O}$ ), and $\mathrm{NaBH}_{4}$, which reacts vigorously with water, aqueous acid, or alcohols, releasing $\mathrm{H}_{2}$. Neither $\mathrm{NaHCO}_{3}$ nor $\mathrm{NaBH}_{4}$ proved soluble in [emim][acetate] (the IL of choice for cellulose dissolution) and so they were added as finely divided solids (3-4 $\mathrm{wt} \%$ ) to [emim][acetate]. The resulting mixtures were dropped or extruded using a syringe pump into water or dilute acid solutions, at temperatures ranging from ambient to $70^{\circ} \mathrm{C}$. Gas evolution from mixtures containing $\mathrm{NaHCO}_{3}$ was slow and little foaming occurred, even at elevated temperatures, but mixtures containing powdered $\mathrm{NaBH}_{4}$ foamed rapidly, forming expanded beads of foamed, regenerated cellulose which could be washed and freeze dried, providing highly expanded materials, Fig. 1. As $\mathrm{H}_{2}$ evolution from decomposition of $\mathrm{NaBH}_{4}$ in contact with water is more rapid in the presence 


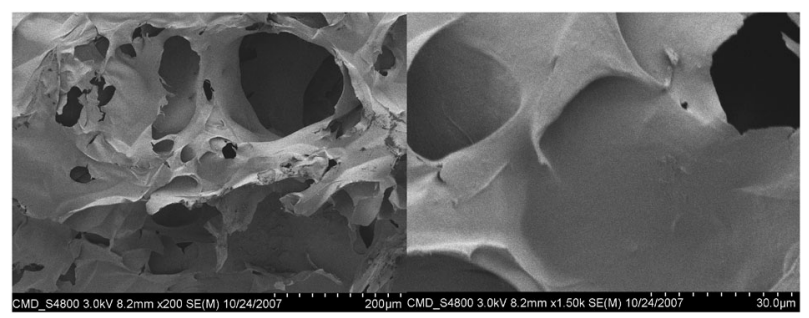

Fig. 1 SEM micrographs of foamed cellulose prepared by dropping a $3 \%$ cellulose in [emim][acetate] solution, mixed with powdered $\mathrm{NaBH}_{4}$, into dilute $\mathrm{CH}_{3} \mathrm{COOH}$ solution (pH $3-4$ ) followed by washing (water) and freeze drying. The walls of the cells are extremely thin and are ruptured in places due to the use of excess foaming agent.

of acid, foams formed by contact with dilute acid solutions were more highly expanded than those formed by contact with pure water.

A series of foamed composite materials were prepared by addition of insoluble filler materials, such as cellulose particles or fibres (Fig. 2), finely divided clays, expanded graphite, titanium dioxide or carbon black, to the cellulose/IL solution. Addition of such fillers provides materials that are much stronger (and more rigid) than the foamed cellulose alone. Notably, in all cases the insoluble (or partially soluble in the case of cellulose fibres) solid fillers remained associated with the cellulose on regeneration and did not escape into the receiving anti-solvent, as evidenced by a lack of solid particles in the receiving anti-solvent (no particles were detectable either visually, or on filtration through glass fibre filter paper). Close examination of scanning electron micrographs of the surfaces of these materials reveals that the solid fillers tend to be coated in regenerated cellulose, Fig. 2.

Decomposition of $\mathrm{NaBH}_{4}$ by reaction with water yields borate salts, which may not be completely removed from the product during washing, thus contaminating the foamed product (while borates may act as flame retardants in some applications, in others borates are considered undesirable). Unavoidably, borate salts contaminate the recovered ILs, rendering recycling of these costly solvents difficult. This, combined with the hazards associated with handling solid $\mathrm{NaBH}_{4}$, led to a search for alternative, more benign, reactive foaming agents.

1-Alkyl-3-methylimidazolium-2-carboxylates, 1, result directly from the reaction of 1-alkylimidazoles with dimethylcarbonate (DMC), Scheme $1 .^{16}$ These stable, isolable,

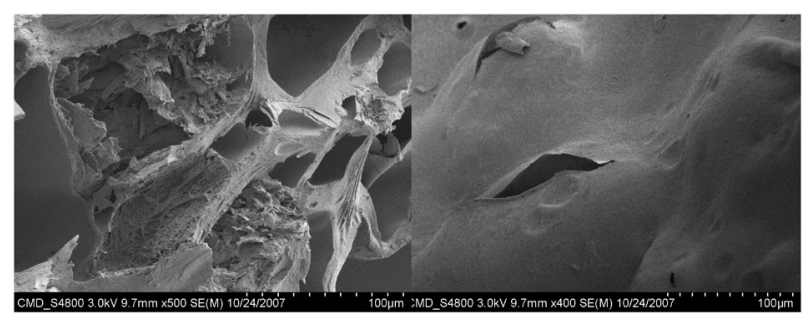

Fig. 2 Cellulose-in-cellulose composite, prepared by adding cellulose particles and $\mathrm{NaBH}_{4}$ blowing agent to a solution of cellulose in [emim] [acetate] followed by extrusion of the mass into $\mathrm{CH}_{3} \mathrm{COOH}_{(\mathrm{aq})}$ solution. $\ddagger$ The external surface of the extruded droplet is smooth (right), but internal cell surfaces show evidence of undissolved cellulose fibres incorporated into the material (left).

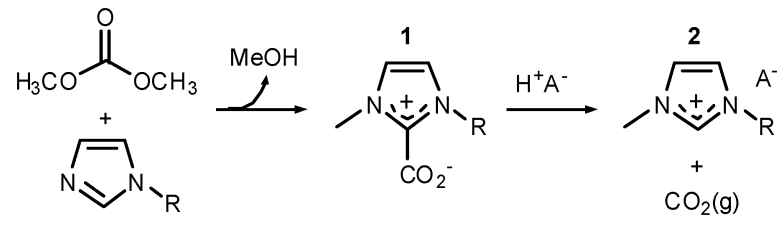

Scheme 1 Reaction of 1-alkylimidazoles with dimethylcarbonate leads to formation of the zwitterionic imidazolium-2-carboxylates, $\mathbf{1}$, which, upon contact with dilute aqueous acid solutions, release $\mathrm{CO}_{2}$ gas, forming an imidazolium ionic liquid as by-product.

zwitterionic salts may be decomposed by contact with aqueous acid solutions to provide an imidazolium salt and $\mathrm{CO}_{2}$ gas. ${ }^{17}$ While compounds such as $\mathbf{1}$ have been described as precursors suitable for the synthesis of halide free ionic liquids, ${ }^{17}$ these have never been considered as potential foaming agents. Clearly where $\mathrm{R}=$ ethyl and the decomposing acid is chosen to be acetic acid, the resultant salt will simply be [emim][acetate], i.e. the ionic liquid of choice as a cellulose solvent, thus providing a foaming agent that simply regenerates the ionic liquid: a "by-productless" foaming agent. This provides an elegant means of foaming without contaminating the ionic liquid recycle stream and, as the ionic liquid must be recycled to maintain both a cost efficient and environmentally friendly process (minimising waste), this is an important step forward in broadening the palette of materials accessible from cellulose dissolved in ILs. It alleviates the need for extra cleanup steps, including removal of foaming agent by-products during IL recycling and thus saves process steps (time and equipment hold-up), energy and materials.

A range of imidazolium-2-carboxylate zwitterionic salts may be prepared and, as 1-butyl-3-methylimidazolium-2carboxylate was readily available and cellulose is reported to be soluble in $[\mathrm{bmim}] \mathrm{Cl}$, this combination was used to test the feasibility of using 1,3-dialkylimidazolium-2-carboxylates as foaming, or blowing, agents. $[\mathrm{Bmim}] \mathrm{Cl}$ is a solid at ambient temperature $\left(\mathrm{mp} \mathrm{ca} .70{ }^{\circ} \mathrm{C}\right)$, but, once a cellulose solution is prepared and combined with the liquid 2-carboxylate foaming agent, this remains liquid as it cools to ambient temperature. Cellulose is not directly soluble in zwitterionic 1-butyl-3methylimidazolium-2-carboxylate, but addition of this blowing agent to the cellulose/[bmim $] \mathrm{Cl}$ solutions did not result in precipitation of cellulose and indeed, served to reduce the viscosity of the cellulose/IL solutions, easing extrusion.

A $4 \%$ solution of cellulose in [bmim]Cl mixed with $c a$. $20 \mathrm{wt} \%$ 1-butyl-3-methylimidazolium-2-carboxylate dropped into $1 \mathrm{M} \mathrm{HCl}_{(\mathrm{aq})}$ solution resulted in vigorous bubbling, yielding foamed beads of cellulose, Fig. 3. The thickness of the cell walls is governed by a number of factors, including those that govern viscosity of the cellulose/IL solution: temperature, cellulose concentration, and IL purity (particularly water content) and those that define both the rate of evolution of foaming gas and the quantity of gas evolved: foaming agent concentration, receiving solution $\mathrm{pH}$ and temperature. Thus, cell wall thickness and surface area may be tuned for a specific application.

As the by-product of the foaming agent is the [bmim] cation paired with the anion derived from the acid $\left(\mathrm{Cl}^{-}\right.$in this case), the anti-solvent receiving solution and any washings were 


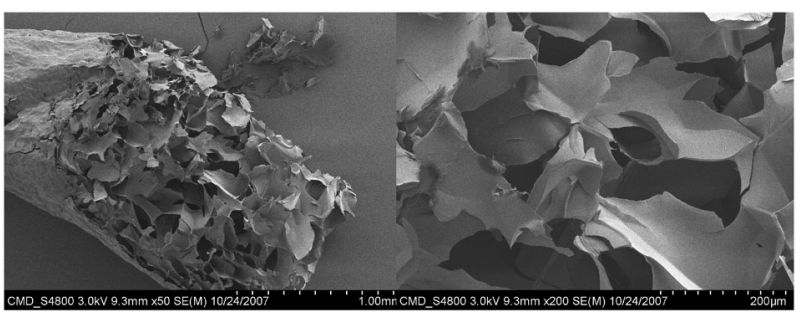

Fig. 3 SEM micrographs of a cellulose droplet foamed using 1-butyl3 -methylimidazolium-2-carboxylate in [bmim] $\mathrm{Cl}$. Thin cell walls do not enclose cells and it is clear that quantity of the foaming agent should be adjusted if a closed cell structure is desired. In addition, if a more dense structure is required, the foaming agent may be reduced and acid concentration decreased to slow the rate of gas evolution.

combined and water removed in vacuo to yield uncontaminated [bmim] Cl for reuse; the by-product of the foaming agent is simply the IL used for cellulose dissolution! As before, a series of composite materials could be produced by combining solid fillers with the cellulose/IL/foaming agent solution to form a mixture.

Zwitterionic 1,3-dialkylimidazolium-2-carboxylates are demonstrated to serve as by-productless foaming or blowing agents for underivatised cellulose dissolved in ionic liquids. Specifically, 1-butyl-3-methylimidazolium-2-carboxylate may be used to foam cellulose dissolved in [bmim] Cl by extrusion into dilute $\mathrm{HCl}_{(\mathrm{aq})}$ solutions, yielding [bmim] $\mathrm{Cl}$ as the foaming agent by-product. The foamed cellulose products are lightweight open cell materials, which may include added fillers to increase strength and rigidity or to alter other characteristics of the product. This "by-productless" methodology for producing high surface area cellulose foams complements the recent discoveries of Rogers et al. and others and provides access to a broader pallette of materials derived from the abundant resource: underivatised cellulose.

Much of this work was carried out as part of a programme funded by the European Community's Sixth Framework Programme, specifically the 'Marie Curie Host Fellowship for the Transfer of Knowledge' Action 'Sustainable Functional Molecules from Renewable Resources via Green Chemistry" (SUSRES MTKD-CT-2005-029644).

\section{Notes and references}

$\ddagger$ In a typical experiment to prepare a cellulose in cellulose composite (the material illustrated in Fig. 2) a $4.431 \mathrm{~g}$ of a $3.1 \mathrm{wt} \%$ solution of cellulose in [emim] [acetate] was blended with $1.174 \mathrm{~g}$ of dried microcrystalline cellulose powder and heated overnight at $100{ }^{\circ} \mathrm{C}$ under vacuum to remove any water. The cooled solution was mixed with $39 \mathrm{mg}$ of finely powdered $\mathrm{NaBH}_{4}$ and extruded from a disposable syringe, in a single tubular mass, into water acidified with $\mathrm{CH}_{3} \mathrm{COOH}$ to $\mathrm{pH}$ 3-4. Evolution of gas occurred and the tubular mass rapidly expanded. "Worms" of expanded cellulose were removed by filtration and washed with water ( 3 aliquots) before freeze drying to yield light, brittle, strong wormlike forms of cellulose in expanded cellulose composite. In a typical experiment to prepare expanded cellulose using the "by-productless" 1-butyl-3-methylimidazolium-2-carboxylate foaming agent a $4 \mathrm{wt} \%$ solution of cellulose in [bmim] $\mathrm{Cl}$ mixed with $20 \mathrm{wt} \%$ 1-butyl-3-methylimidazolium-2-carboxylate was extruded dropwise into $1 \mathrm{M} \mathrm{HCl}_{(\mathrm{aq})}$. Evolution of gas occurred and the droplets rapidly expanded. Droplets of expanded cellulose were removed by filtration and washed with water (3 aliquots) before freeze drying to yield light, brittle teardrop shaped droplets of expanded cellulose, with smooth outer surfaces. The ionic liquid [bmim] Cl was recovered by evaporation of filtrate and washing in vacuo to yield [bmim] Cl slightly contaminated with cellulose breakdown products (polysaccharide oligomers).

1 The viscose process is a multi-step process encompassing: steeping (soaking in $\mathrm{NaOH}$ solutions); pressing; shredding (to expose greater surface area); aging (oxidation and depolymerisation); xanthation (reaction with $\mathrm{CS}_{2}$ to produce regions of cellulose xanthate); dissolution (in dilute $\mathrm{NaOH}$ solution); ripening (the reversible xanthation reaction proceeds to dissolve the more crystalline regions); and 2-stage regeneration (a combination of heat and acid baths, often incorporating $\mathrm{ZnSO}_{4}$ to aid coagulation, is applied to decompose the xanthate, yielding cellulose).

2 V. Ottorepetz, Great Britain Patent, GB191323196, 1914.

3 E. Hubert, Kolloid-Z., 1931, 57, 253-258.

4 R. Skutezky, Great Britain Patent, GB308838, 1930.

5 H. Firgo, S. Ambrosch and A. Schweigart, US Patent, US6007750, 1999.

6 R. P. Swatloski, R. D. Rogers and J. D. Holbrey, PCT Patent Application, WO03029329, 2003; R. P. Swatloski, R. D. Rogers and J. D. Holbrey, US Patent, US6824599, 2004; R. P. Swatloski, S. K. Spear, J. D. Holbrey and R. D. Rogers, J. Am. Chem. Soc., 2002, 124, 4974-4975.

7 M. B. Turner, S. K. Spear, J. D. Holbrey and R. D. Rogers, Biomacromolecules, 2004, 5, 1379-1384.

8 M. B. Turner, S. K. Spear, J. D. Holbrey, D. T. Daly and R. D. Rogers, Biomacromolecules, 2005, 6, 2497-2502.

9 J. H. Poplin, R. P. Swatloski and J. D. Holbrey, Chem. Commun., 2007, 2025-2027.

10 N. Sun, R. P. Swatloski, M. L. Maxim, M. Rahman, A. Harland, A. Haque, S. K. Spear, D. T. Daly and R. D. Rogers, J. Mater. Chem., 2008, 18, 283-290.

11 G. Ebner, S. Schiehser, A. Potthast and T. Rosenau, Tetrahedron Lett., 2008, 49, 7322-7324.

12 Q. Zhao, R. C. M. Yam, B. Q. Zhang, Y. Yang, X. Cheng and R. K. Y. Li, Cellulose, 2009, 16, 217-226.

13 K. Massonne, G. d Andola, V. Stegmann, W. Mormann, M. Wezstein and W. Leng, European Patent, EP1994058, 2008; K. Massonne, V. Stegmann, G. d Andola, W. Mormann, M. Wezstein and W. Leng, European Patent, EP2035460, 2009; K. Massonne, V. Stegmann, G. d Andola, W. Mormann, M. Wezstein and W. Leng, European Patent, EP2038307, 2009.

14 M. Deng, Q. Zhou, A. Du, J. van Kasteren and Y. Wang, Mater. Lett., 2009, 63, 1851-1854.

15 V. Stegmann, K. Massonne, M. Maase, E. Uerdingen, M. Lutz, F. Hermanutz and F. Gaehr, German Patent, DE102006035830, 2008.

16 (a) J. D. Holbrey, W. M. Reichert, I. Tkatchenko, E. Bouajila, O. Walter, I. Tommasi and R. D. Rogers, Chem. Commun., 2003, 28-29; (b) M. Aresta, I. Tkatchenko and I. Tommasi, Ionic Liquids as Green Solvents: Progress and Prospects, ACS Symp. Ser., 2003, 856, 93-99.

17 M. Smiglak, J. D. Holbrey, S. T. Griffin, W. M. Reichert, R. P. Swatloski, A. R. Katritzky, H. Yang, D. Zhang, K. Kirichenko and R. D. Rogers, Green Chem., 2007, 9, 90-98. 